\title{
Financial Shared Service Center Development in China
}

\author{
Lishu Zhao ${ }^{1}$, Shanyue $\mathrm{Jin}^{2}$, Weidong Huang ${ }^{3}$ \\ ${ }^{1}$ MA Student, Graduate School of Business Administration, Gachon University, Korea, \\ 756145258@qq.com \\ ${ }^{2}$ Associate Professor, Collage of Business, Gachon University, Korea, jsyrena0923@ gachon.ac.kr \\ ${ }^{3}$ Ph.D student, Collage of Business, Gachon University, Korea, 2450563017@qq.com \\ Corresponding author: Shanyue Jin
}

\begin{abstract}
Along with the increasingly fierce competition in the market, rising labor costs and other reasons, large enterprises gradually began to adopt financial sharing center of this new type of financial organization. These are the scattered around the financial department together set up financial sharing center, unified organization and operation management, to save financial and human cost, improve the efficiency of financial processing, reduce the financial risk control, etc. Starting from the related concepts, characteristics, and methodology system of financial sharing center, this paper analyzes and summarizes the related theories of financial sharing center. Then, taking ZTE Group's financial sharing center as the exploration point, this paper discusses the establishment, operation and problems of the financial sharing center in Chinese enterprises based on practical cases, and gives corresponding Suggestions based on the actual situation of ZTE Group and the reference of relevant materials. The main research contents of this paper are as follows: First, based on the references and their own sorting and induction, the financial sharing center related concepts are discussed. Secondly, it analyzes the existing financial management problems before the establishment of THE FINANCIAL sharing center of ZTE Group, as well as the construction plan of the financial sharing service center, mainly including internal accounting, organizational structure, information system and sharing ability, and finally summarizes the important success factors of the establishment of ZTE financial sharing center. Thirdly, taking THE FINANCIAL sharing center of ZTE Group as a refract point, this paper makes an in-depth discussion on possible problems and optimization ideas in the establishment and operation of the financial sharing center of Chinese enterprises.
\end{abstract}

Keywords: Finance, Sharing, Service, Approach, ZTE, China

\section{Introduction}

Since the 1980s, economic globalization has been expanding capital all over the world, and the competitive environment of enterprises has changed greatly. At the same time, science and technology and information are also developing rapidly. Driven by these forces, more transnational groups appear, and the existing ones are also increasing their pace of expansion. As an important department providing support for enterprise accounting and operation, finance naturally needs to keep pace with the times, improve service efficiency and quality, and create more value for enterprises. It is not difficult to find that with the increase in the number of subsidiaries and branches of multinational groups. A lot of repetitive work has appeared in accounting, such as reimbursement, accounts payable accounting and so on. Under the traditional accounting method, each branch needs to be equipped with a complete

Received: October 04, 2020; $1^{\text {st }}$ Review Result: November 23, 2020; $2^{\text {nd }}$ Review Result: January 10, 2021 Accepted: February 26, 2021 
accounting process, which greatly increases the personnel cost. At the same time, as branches are often far away from the headquarters, it is not conducive for the headquarters to timely monitor their financial and operational conditions, and there are also risks of financial fraud, which increase both operational and financial risks. In order to better serve the development of enterprises, help enterprises to save costs, efficient completion of enterprise Financial work, a new accounting Service model emerged - Financial Shared Service, referred to as Financial sharing.

Financial sharing service is to separate the non-core parts of the traditional accounting process with high repeatability and process them uniformly in the established Financial sharing center (FSSC). That is, the original old accounting division of labor resources integration, to achieve the standard, process, high efficiency, low cost, improve the overall operating efficiency of enterprises, to help enterprises better development.

As a new organizational form, financial sharing center has only been gradually popular in the past 30 years, and it is mostly used in multinational groups or large multi-subsidiary organizations or subsidiaries. As the financial sharing center is quite different from ordinary financial departments in terms of organizational process and personnel allocation, there are differences and advantages, and inevitably there are also many problems.

As the world's leading provider of integrated communication and information solutions, ZTE group has a number of subsidiaries and subsidiaries. Due to the inconsistency of financial procedures, the subsidiary's financial and related departments are in their own hands, and there is no unified process and standard for centralized control, which is not conducive to the implementation of the group's overall strategy. Financial personnel miscellaneous and varying levels of financial work efficiency is low, professional division of labor is not obvious. The information integration is not perfect and the advanced accounting system is not used. As a result, accounting professionals need to input data repeatedly, resulting in the waste of human resources. In this case, the group headquarters' control ability to each branch is also low, the capital management cannot achieve the integration advantage, the financial risk headquarters is difficult to detect and track in a timely manner, the implementation of financial transformation strategy becomes imperative.

Survey (from financial Shared services present situation and prospect of Chinese enterprises by deloitte"), China's enterprises in promoting the transformation of financial strategy, the three major tasks for priority cost savings, process reform, internal control and risk management, and financial Shared services becomes just push this three major tasks of the effective means to achieve the ideal. Therefore, in order to strictly control risks, give play to capital integration and economies of scale, improve financial efficiency, and save financial costs, ZTE Group has made the decisions of integrating financial personnel, adjusting financial structure, standardizing financial procedures, and uniformly implementing standards. It has set up a financial service sharing Service Center (FSSC).

The purpose of this paper is to study the problems and optimization of financial sharing center, starting from a larger concept - service sharing center is the source of financial sharing center. Through the review and study of relevant literature, it is found that service sharing is aimed at reducing costs and improving efficiency, and it can accelerate the standardization process of enterprises and improve the technical level of service sharing personnel. However, there is also the problem of high start-up cost. Therefore, you can understand one of the concepts of being a service sharing center, the nature and existing problems of establishing financial sharing center.

Using literature analysis and case analysis, this paper discusses the reason, construction plan and successful factors of ZTE group's establishment of financial sharing center. Then, starting from the current situation of financial service sharing service centers of Chinese enterprises, this paper analyzes the problems and the causes of the current problems in the aspects of accounting information quality, human resources, risk control, organizational structure, sharing ability, financial system and information system. Then by combining the theory of financial sharing center and the enlightenment of ZTE group's 
financial sharing center, the corresponding optimization method is given. Finally, by sharing ZTE group financial center as an example, the common problems of Chinese enterprise financial Shared services center as the guidance, the optimized scheme for reference, are summarized, intended to give other plans to set up the center of the financial Shared enterprises and financial Shared center has been set up, but facing the same problem enterprises some reference to temporarily does not appear similar problem some revelation of enterprise, hope that they can focus on the further optimization of the financial center of Shared.

The innovation of this paper are as follows:

1) Enrich relevant theories of financial sharing center. As the financial sharing center is gradually applied by large enterprises, the related researches on financial service sharing emerge one after another. After reading many papers on financial sharing centers, the researchers found that most of the studies focused on the elaboration and establishment of related concepts of financial sharing centers. Based on the research content of this paper, it is about the problems and optimization of financial sharing center. Therefore, the researcher summarizes, refines and summarizes the relevant literature and data collected and studied in this part. The related theories of financial sharing center are enriched.

2) Combine relevant theories and practical applications of the financial sharing center. Due to the researchers working in ZTE corporation financial sharing center family, for financial sharing center had certain understanding, so the researchers from the establishment of ZTE corporation financial sharing center and success factors, in the center of the Shared with financial, on the basis of relevant theories in combination with the present problems of the Chinese corporate finance Shared optimization scheme is put forward. This is the combination of theory and practice of innovation.

\section{Theorical Background}

\subsection{Concepts Related to Financial Shared Services}

The concept of financial sharing is based on a more widely used concept called "service sharing". Therefore, before discussing the concept of financial sharing, we first comb through the concept of service sharing. Sharing service is the enterprise that used in different business units of organization and resource integration, will need to play such as financial or human resources management activities from the business units of the original professional skills, to cancel the original independent back office, and then provide uniform service of specialized entity, the entity is called a Shared service center. This way of resource integration can optimize enterprise resource allocation and enhance the core competitiveness of enterprises. In Essentials of Shared Services, Bryan Bergeron (2003) argued that a Shared service center is a semi-autonomous business unit with a dedicated management department, which achieves the purpose of saving costs, improving efficiency, creating value, and improving the service quality of internal customers through the optimization of human, capital, time, and other resources.

Financial sharing center, also known as financial service sharing Center, is a branch of service sharing Center, based on the concept of service sharing. Bergeron believed in the concept of financial sharing service that the financial sharing center in theory was to cancel the original Finance of each subsidiary and set up a new group of financial sharing center, which was responsible for the financial accounting of the original subsidiary. They were unified under the leadership of the group company, but existed independently of the subsidiary. The sharing center will deal with the financial accounting uniformly according to the standardized process and keep quite close contact with the subsidiary. Specifically, it is to separate the non-core parts with high repeatability in the traditional accounting process (such as reimbursement, accounts payable accounting, etc.) and conduct unified processing in the established financial sharing Center (FSSC). Because of the traditional accounting method, each branch need is equipped with a complete accounting process of post personnel, this new form of organization is the 
original old accounting division to resource integration, up to standard, process and high efficiency, reduce cost at the same time the purpose of facilitating their financial and operational headquarters timely monitoring, reduce the management risk and financial risk[Fig. 1]. The emergence of financial sharing center can redivide the original financial system into three levels of headquarters finance, Shared finance and business finance, and promote the company's original financial system to gradually change from accounting finance to management and value creation. The organizational model of financial service sharing can be divided into entity property sharing service center, mixed property sharing service center and virtual financial sharing center. Virtual property service sharing center can change the value chain, organizational structure and organizational behavior of production and operation mode, which will be the development direction of financial sharing center in the future.

\subsection{Development History of Financial Sharing Center}

\subsubsection{Development History of the Financial Sharing Center}

Since the early 1980s, when Ford Motor created the first ever financial sharing center model and achieved great success, financial sharing centers have mushroomed and been followed by large enterprises. The main development process includes: in the late 1980s, dupont and GENERAL Electric established financial sharing center; In the 1990s, HP and IBM also successively used the form of financial sharing center. With the establishment of financial sharing center by MOTOROLA in Tianjin in 1999, the financial sharing center really entered Asia. After the turn of the millennium, the form of Shared financial center was gradually popularized in China. In 2003, Accenture established the Asiapacific Financial Sharing Center in Shanghai. In 2004, HP established the North Asia Pacific Financial Service sharing Service Center in Dalian; In 2005, ZTE established the financial sharing center, which was the first enterprise in China to establish the financial sharing center. In 2006 and 2007, Sino-British Life and Pfizer established financial sharing centers respectively. Therefore, the financial sharing center is gradually applied and emulated by more enterprises.

[Fig. 1] Financial Sharing Center Model Diagram

(Source: The Financial sharing service Baidu Encyclopedia)

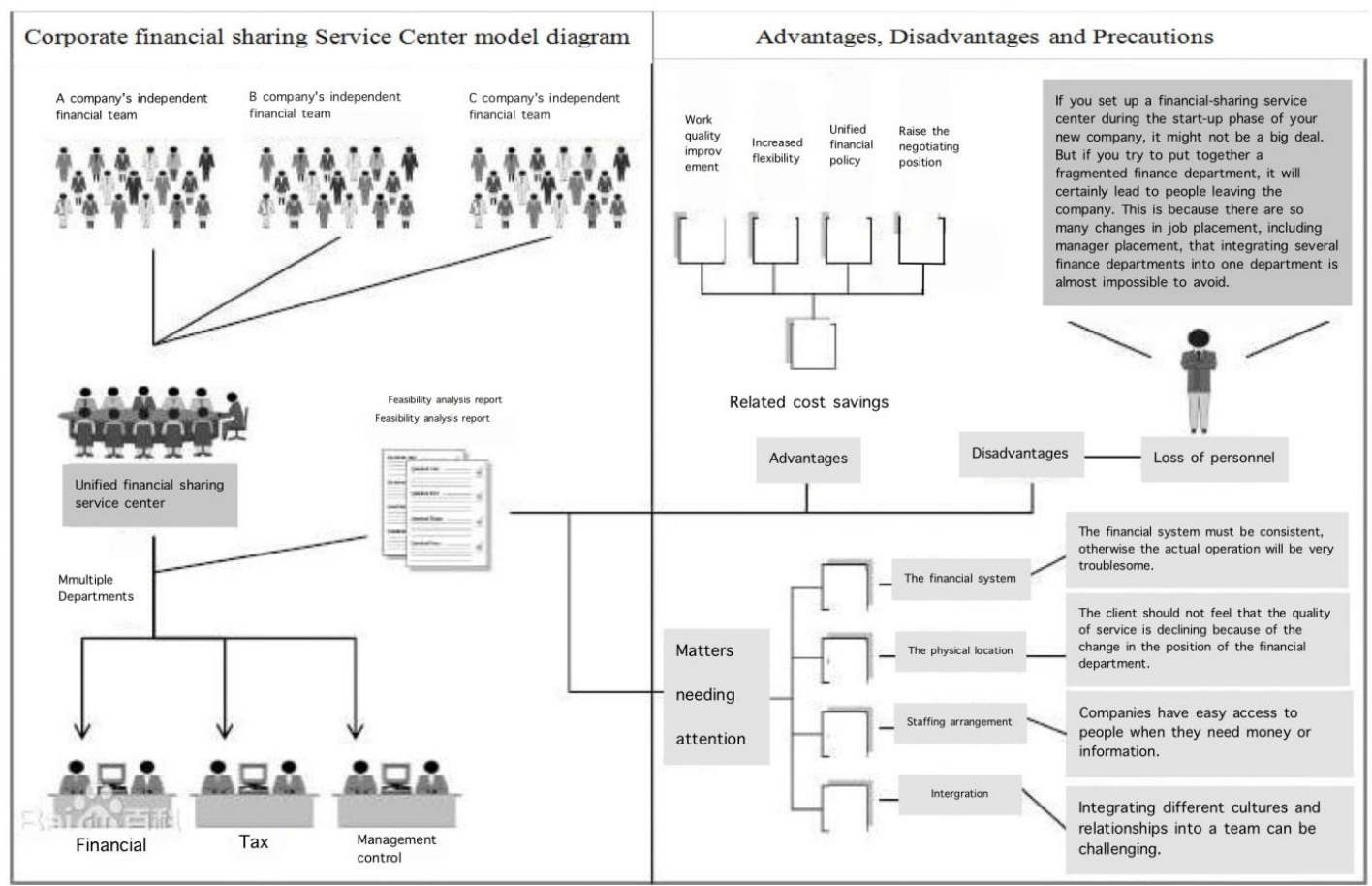




\subsubsection{Development Status of Financial Sharing Center}

According to ernst \&young released 2015 annual "China enterprise financial Shared services service industry development present situation, and deloitte released by the China regional financial Shared services present situation and outlook, overall, since 2010, the financial service Shared service center in China present high growth momentum, and built in large and medium-sized enterprises, less application in small businesses; Geographically: Due to the cost advantage of the central and western regions and the gradual improvement of relevant supporting facilities, the financial service sharing service center is shifting from the developed regions in the east, especially the Bohai Rim cluster, Yangtze River Delta and Pearl River Delta cluster to the provincial capitals in the west. Distribution business scope: related business, now into the financial center of Shared out in the former process and sequence of six respectively "expenses", "accounts payable", "general ledger", "receivables" and "cash settlement" and "financial reporting", this and global research results, the financial center of Shared process, low value and keep high value flow in the headquarters of financial and business financial management; Personnel management: On the whole, the baseline standards for employing people in Financial service sharing service centers in China are relatively low, and most of the financial personnel have bachelor's degrees. However, there is no cooperative relationship between financial service sharing centers and universities in the vast majority of China. Operation management: The main performance measures of financial service sharing service center in China are "business processing efficiency", "service satisfaction", "business quality" and "unit business processing cost" respectively, while "service scope", "input/ output" and "staff turnover" pay less attention to.

Realize the basic consensus: at present, Chinese companies have already have a large enterprise branch, willing to through the establishment of the center of the financial Shared manner, with the help of a standardized process to promote the transformation of financial process efficiency and financial functions, has reached to help saving the cost of enterprise management and financial liberation of personnel engaged in the purpose of higher value-added work, eventually improve enterprise's overall value.

\subsection{Features of Financial Sharing Center}

The features of the financial sharing center are mainly divided into six points, which are: centralized training of financial personnel, unified financial standards and procedures, centralized sharing of financial information, centralized control of financial risks, centralized allocation of capital management, centralized decision-making of financial strategies.

1) Centralized training of financial personnel

Under the original financial system, different branches are relatively independent of each other. The financial leader of each branch may have different judgment to the same financial processing, financial management habits are not the same. As a result, each branch has its own accounting treatment, financial process, risk judgment, capital management and so on. Under the concept of financial sharing center, financial personnel of each branch are disassembled, and competent financial personnel are selected to conduct centralized processing of the accounts of each branch in a specific location. The branch will retain only a few financial managers who need to transfer bills and coordinate the company's finances. This completes the financial personnel from the redundancy to the refinement, from the level varies to the talented person's conversion. At the same time, in this mode, also facilitate the company's follow-up training and training management of financial personnel.

2) Unified financial standards and procedures

Under the mode of branch, the financial process and financial standards of different branches are not unified. After the establishment of the financial sharing center, the headquarters and related personnel can combine the characteristics of the enterprise and the national financial standards and other financial 
flows. That is, the relevant policies and standards of finance are unified.

3) Centralized sharing of financial information

Because the financial personnel who handle the accounts are concentrated in the financial sharing center, they are geographically separated from local enterprises. Therefore, local financial personnel need to collect financial information, relevant documents, invoices and so on. Send to the financial sharing center by scanning, fax, mail, etc. Therefore, the financial staff of the financial sharing center can simultaneously grasp and share the financial situation of different branches.

4) Centralized control of financial risks

Since financial information can be centrally reflected in the FINANCIAL sharing center, the financial sharing center professionals can have a clearer understanding of the financial situation of each company. In this way, according to the situation of the country and the industry, various risks that may be coming can be expected in advance and corresponding measures can be given to avoid them. The financial loopholes of a branch can also be observed more directly and intuitively. For the benign development of the company's economy has laid a good foundation.

5) Centralized allocation of fund management

Under the general financial system, the funds of each branch are retained in the local financial department. Funds are managed and allocated by the local finance department. However, under the financial sharing center model, all idle funds are placed in the sharing center, and only petty cash is kept in the place where the branch belongs. The financial sharing center can give full play to the scale advantage of these funds, thus leveraging larger resources.

6) Centralized financial strategy decision-making

Financial leaders can not only timely understand the operation of each financial unit through the financial sharing center, but also facilitate the distribution and implementation of the group's overall financial strategy.

\subsection{Methodology System "Sports Model"}

The methodology system widely used by enterprises in constructing financial sharing center is "SPORTS model". The model covers six aspects of sharing construction, starting from site, process, organizational personnel, laws and regulations, technology, and service relationship management, and covers all important fields of promoting the construction of financial sharing center.

1) S--Build a financial Shared Service center (Site)

To separate and integrate the original financial personnel and establish a financial sharing center is bound to take into account the location of the financial sharing center. If the location decision is wrong, it will directly or indirectly affect the revenue and service quality of the service sharing center. Generally speaking, the choice of financial sharing center needs to consider three principles: proximity principle, that is, keeping a close distance with other business centers to facilitate information transmission; Customer service oriented, geographically close to the business center, in order to better serve the "customers" of the "center"; The principle of cost first should consider the operation cost of the upfront investment and future operation, labor price and advantages, local information technology infrastructure level, etc.

\section{2) P--Process}

The core of Shared service is the sharing of process, so it is particularly important for the reorganization and construction of financial process. To branch or subsidiary of the group, the finance department of the original process analysis, identification, improvement and optimization in the process of combining financial sharing center of business, integration into the corresponding physical flow, cash flow, information flow, etc., will be to restore process standardization, scientific, process of the enterprise for the optimization design of the "end-to-end", eventually to develop a rigorous unity, is 
conducive to implement the standardization process.

3) O--Organization and People (Organization)

The foundation to ensure the smooth and efficient operation of the financial sharing center is the organization and personnel, and the foundation to build a standardized process. Also need to configure the process requirements and configuration of the relevant personnel. Therefore, it is necessary to divide different professional groups and support groups in the sharing service center according to different business functions, and reasonably match corresponding personnel to form the organization and personnel of the financial sharing center. When establishing the organization and personnel system of the financial sharing center, organizational change theory and personnel allocation calculation method are often used to assist to set the goal of organizational change, plan the path of organizational change, calculate the expected scale of personnel allocation, and plan and execute the recruitment and training methods.

4)R--Regulatory \& Legal

The operation mode of financial sharing center also needs to consider the requirements of laws and regulations, so as to build a legal entity structure that meets the requirements of laws and regulations. In addition, it is also necessary to actively explore whether there are relevant policies and rules and regulations that are conducive to the development of the industry and the company, as well as how to correctly use the policies to carry out reasonable tax avoidance, etc.

5)T--Technology

The information technology platform is the guarantee for the smooth operation of the financial sharing center. Relying on the application of IT and information technology, advanced image system, efficient ERP software application, big data processing and other technologies can achieve data batch and accurate processing, can reflect the advantages of financial sharing organization form.

6)S--Service Relationship Management

Service level agreement (SLA) is widely used as a standard to guide the service relationship and operational effectiveness, such as service and settlement standards between the service parties and the served parties. Service level agreements (SLAs) are the bridge for communication and evaluation of service centers and units. Service level agreements (SLAs) that are recognized and measurable by both the service parties and the service parties should be worked out at the beginning of establishment and operation.

\subsection{Literature Review}

\subsubsection{Overview of Research on Shared Services}

As for the meaning of Shared service, Barbara. Quinn (2000) has this understanding: the emergence of Shared service means the emergence of a new management concept, that is, to provide services to meet the needs of customers, charge fees for services, and ensure the work of relevant departments by maintaining clear service objects[1].

Moller (1997) proposed that in order to implement Shared services, enterprises should first set up a new organizational unit, namely a Shared service center, through which Shared services can be carried out and resources can be reasonably allocated to provide better financial support for enterprises[2].

BergeronBryan put forward in 2003, Shared services is a part of the enterprise existing business functions separated from the original post, integrate into a separate unit, for the enterprises of other organizations to provide a professional and efficient service platform, and help enterprises to reduce cost and value of regulations, improve service quality at the same time, provide enterprises with a clear structure of operating mechanism[3].

Andrew Kris and Martin Fahy studied various forms of Shared service centers in their monograph written in 2004, discussed the influence of good design on the efficiency of Shared services, and 
explained how organizations can seize the opportunities brought by Shared services, reshape the business development process, make reasonable plans and implement corresponding plans[4].

\subsubsection{Research Overview of Financial Shared Services}

In terms of financial sharing service research, Domestic scholar Zhang Xingyan (2007) proposed that although financial sharing service centers are mostly applied to large enterprises at present, it does not mean that small and medium-sized enterprises cannot benefit from financial sharing. As long as a business runs different businesses, and those businesses are financially supported, the business can try to implement Shared services

It is obvious that Chinese enterprises are expanding in the process of development. Chen Lika (2014) proposed that under such circumstances, many deep-seated problems, such as how to reform the financial management of enterprises, need to be solved urgently. For example, the operation and management problems of enterprises and the continuous expansion of enterprise scale will directly lead to the increase of enterprise operating costs and the upgrading of management difficulties. Another example is the backward concept of enterprise management. The scale of some domestic enterprises has reached a critical point, but the management has not made innovations and breakthroughs in the management mode, which leads to the slow expansion of enterprises. Therefore, it is necessary to study the operating mechanism of financial Shared services[5].

Zhang Yuqiang (2014) has such a view on financial sharing: Domestic enterprises' desire to develop financial sharing has the need to meet their own management development, and the purpose is to accelerate their business development strategy. This difference in demand makes domestic enterprises have a certain difference in the pursuit of goals when developing financial sharing compared with foreign enterprises which are more mature in this aspect. In addition, the implementation of financial sharing by enterprises is not only aimed at reducing their own financial processing costs, but also to facilitate the distribution of financial resources, help financial transformation, and facilitate the decisionmaking and strategy of enterprises[6].

Li Wen, Liu Dongjin (2015) in the domestic and foreign enterprise financial sharing center after the case study conclude that Shared services since appeared, the seat are constantly expanding the scope of business, not only in dealing with the basis of standardization of accounting work, has developed into the more advanced decision support and risk management, and other functions. In financial Shared services operation process, the basic accounting work is broken down by induction, every employee in the process to one of the modules shall be carried out in accordance with the standard operation, the enterprise distribution in each region of the unit with the same reference standard and mode, originally the jagged function provides the specialized division of labor, for the enterprise provides a possible economies of scale. The establishment of enterprise financial sharing center is of considerable help to standardize enterprise basic management, accelerate the transformation of enterprise management and control mode, improve management accounting decision-making and enhance enterprise competitiveness[7].

Jian Xiaohui (2014) proposed that according to the different nature of work in the financial Shared service operation mechanism, it can be divided into accounting function and control function. Accounting functions, by means of routine and irregular special inspections, to guard against the risk of distortion of financial information and risks in the business process; The control function needs to be implemented by establishing a comprehensive supervision, control, evaluation and accounting system within the enterprise."[8].

Zhou Huazhu (2015) believed that financial sharing service could provide enterprises with the ability to quickly realize operation in the process of expansion, integrate newly established subsidiaries and other units into the system quickly, and realize cost saving while expanding. On the basis of unified 
standards and procedures, promote the standardization of the enterprise's overall business, reduce the difficulty of management, and strengthen the intensity of control[9].

Li ganlin,Zhang qinglong (2012) through the study and put forward, from the perspective of financial perspective, financial Shared services preliminary running, just completed the separation of the functions in the aspect of workflow, then how should continue to promote the transformation of financial, explore the development trend of financial share is that we need to focus on to discuss and solve the problem ". After summarizing local practices[10]. He Ying (2013) proposed three trends of financial sharing: one is to provide decision support through system updating; The second is to reduce costs by optimizing processes; The third is to provide services that customers need. Whether for the purpose of improving the management level of enterprises or for the development of their own business, financial sharing will undoubtedly shoulder the responsibility of exploring the financial prospect after financial concentration[11].

Jin Chunhua (2007) pointed out in their research that the operating mechanism of Shared services should include: service orientation, information communication, transaction costs, assessment incentives, etc. In the summary of the content, it is proposed that the improvement of the operating mechanism of Shared service can be carried out from the perspectives of structure, technology and environment[12].

After studying the current situation and existing problems of the operating mechanism of Shared services, Long Min (2009) pointed out that enterprises should implement Shared services according to their actual advantages, grasp the key points, improve the information platform, improve factors such as incentive, supervision and guarantee, and give play to their respective functions effectively.

Zhang Qinglong, Zhang Chunxi (2012) put forward new information platform is bigger, it will cost you given the high degree of informationization of domestic enterprises have more or less with a set of accounting information system, in building operation information sharing service platform, no need to abandon the existing information system, can be in the original foundation take the essence to the dregs, realize the organic combination between old and new, promote and perfect the information integration[13].

Through research, Zhang Chunxia (2014) found that the operation mechanism is characterized by professionalism, service, technology, uniformity, scale, protocol, etc. Information system is the basis for its successful implementation. In the current operation mechanism, the incentive and performance evaluation system should be improved.

Zhang Qinglong (2012) pointed out that after the establishment of the operation mechanism, followup safeguard measures should be taken to maintain its effective operation, including the management of employees, processes, organizations and risks[14]. Zhang Ying (2015) pointed out that there are still some imperfections in the operation mechanism, which are mainly manifested in process problems, personnel problems, risk control and scale effect problems.

\section{Case Study Analysis: ZTE Group Financial Shared Service Center}

\subsection{Case Background}

Founded in February 1985, ZTE is the world's leading communication service provider. ZTE is in a leading position among domestic communication equipment listed companies, and it holds many subsidiaries and branches. Its "going out" strategy, initiated in 1995, continues to promote the expansion of ZTE's business. ZTE has a place in the overseas market, as its percentage of international revenue as a proportion of total business income is increasing year over year; additionally, its market influence both at home and abroad is expanding. This growth did not come without "growing pains," however: during the development process, information was received slowly, which frequently led to decision-making 
failures; other adverse factors appeared increasingly, and they seriously affected the growth of the ZTE enterprise group.

To address similar problems, other enterprises in other countries worldwide have built financial sharing centers. In 2006, for example, CCCC reformed the financial sharing mode of the group, and completed by the end of 2015 its own financial sharing mode reform.

\subsection{Analysis of Financial Management Problems}

\subsubsection{Lack of Information Transmission}

In the traditional financial model, general financial information is reported and summarized by subordinate branches. This process is more complex than one where information is centrally integrated; additionally, such information tends to lack timeliness, and it can be easily distorted or feature other problems. In any case, since these subsidiaries (i.e., branches) are located worldwide, information systems are separate and the financial system inconsistent, rendering it impossible to achieve close connections with the financial system of the head office. This lack of connection gives rise to an enterprise financial system that is divided into independent data subjects. This state of affairs makes it difficult for the head office to obtain complete financial data and information in a timely fashion, making it impossible to effectively control or make decisions about the branches.

\subsubsection{The Operating Cost of ZTE's Financial Department is too High}

ZTE's overall scale continues to expand. Under the traditional financial model, ZTE's subsidiaries, branches, research and development departments, and other business units worldwide have established their own independent financial departments. As the company expands, the number of financial personnel grows, and their segmentation across these multiple departments is driving up operating and human costs, ultimately incurring substantial financial costs for the company.

\subsubsection{The Scope of Application is Limited.}

Before the financial sharing service system was put into use, ZTE's subsidiaries were independent, and different account structures were established and used, making it difficult for the company to collect financial information. At the end of each month, every company needs to spend a lot of time and energy to prepare and report financial statements twice. As the ZTE group develops, its business continues to diversify, its organizational levels increase, and its business processes become cumbersome. The financial department no longer needs to be independent, but resource integration is needed if personnel are to avoid making mistakes-mistakes that can damage the operational efficiency of the financial department of the overall group. Within such a complex organizational layout, the establishment of a financial shared service center can be very effective in terms of reducing group costs and improving financial service quality.

\subsection{Scheme of the ZTE Group Financial Shared Service Center}

Due to the complicated financial processing situation of each branch adopts different data processing rules, resulting in inconsistent information processing and summary, and there are also deviations in financial indicators' performance assessment and other aspects. In the process of implementing the financial shared service mode, a traditional financial system should be improved, and financial coding, accounting information, financial systems, and business processes should be made more standardized. Such a mode not only supports centralized financial accounting at a later date: it also strengthens the management concept of shared services. However, multiple regions will differ in terms of the market 
environment, and frequently these differences are unique. For this reason, a unified financial system should consider the unique contexts inherent in each business region.

Second, enterprises undertake centralized network management to eliminate traditional decentralized management. Use the network platform to effectively connect subsidiaries, branches and parent companies, they can replace the original scattered functions of the financial department with an easily centralized business process, and in this way bring about the centralization of financial elites in terms of book-processing and financial analysis. Some regions have unique regional and business characteristics and are given certain financial treatment rights in line with local conditions.

Third, ZTE replaced its traditional ERP system with an ERP network system to facilitate financial sharing standardization. In the financial sharing mode, the financial functions of some neighboring areas or within the same areas can be integrated to reduce the overall operating costs. Generally speaking, integration is the sharing and merger of high and low, that is to say, high market and high other subsidiaries against low market and company.

Finally, survival of the fittest. With the development of marketization, ZTE must constantly improve its financial sharing ability. Terminal subsidiary financial institutions are at the front end of the business and most close to the market information, while the group sharing center is the end of the confidence summary, separating the business from the market and only through data analysis. To solve this problem, ZTE improves the terminal financial information timely feedback system, promotes the active exchange of key talents, and improves the ability of financial sharing. At the same time, the platform consolidates the previously complex audit work into a clear information flow through the system setting process, so as to ensure the transparency and accuracy of financial data.

\subsection{Important Success Factors for ZTE's Financial Shared Service Center}

\subsubsection{The Optimization of its Organizational Structure}

The ZTE group's overall organizational structure is complex, with the financial departments of each branch being independent and not subordinate to each other; this structure's complexity means that financial information is not transmitted in a timely fashion, and that the financial information group will necessarily suffer from resource allocation inefficiency. To resolve this problem, ZTE optimized its organizational structure, improved its decentralized financial department, and established a group-level financial shared service center. By resolving the problems inherent in its financial process, ZTE can facilitate the timely and efficient transfer of financial information for financial work purposes. In the process they can bring about an efficient and concise organizational structure, reduce operating costs, promote financial sharing and enterprise development, and create more value.

By comparing the data of ZTE before and after the establishment of the Shared service center [Table 1], we can see that before 2005, the number of managers increased year by year, but the growth of the total assets of the enterprise was not satisfactory.

[Table 1] Data Before and After the Establishment of the Service Ccenter

\begin{tabular}{|c|c|c|c|c|c|c|}
\hline Year & $\begin{array}{c}\text { Number of } \\
\text { managerial } \\
\text { personnel }\end{array}$ & $\begin{array}{c}\text { Growth rate } \\
\text { of managerial } \\
\text { staff }\end{array}$ & $\begin{array}{c}\text { Overheeads } \\
(* 1000)\end{array}$ & $\begin{array}{c}\text { Growth rate of } \\
\text { overheads }\end{array}$ & $\begin{array}{c}\text { Total assets } \\
(* 1000)\end{array}$ & $\begin{array}{c}\text { Growth rate of } \\
\text { total } \\
\text { assets }\end{array}$ \\
\hline 2002 & 1261 & & 1947733 & & 12216893 & \\
\hline 2003 & 1710 & $35.61 \%$ & 2572744 & $32.09 \%$ & 15766955 & $29.06 \%$ \\
\hline 2004 & 2200 & $92.98 \%$ & 3899003 & $51.55 \%$ & 20830022 & $32.11 \%$ \\
\hline 2005 & 3774 & $14.36 \%$ & 3137066 & $-19.54 \%$ & 21779131 & $4.56 \%$ \\
\hline 2006 & 5435 & $44.01 \%$ & 1244683 & $-60.32 \%$ & 25760693 & $18.28 \%$ \\
\hline 2007 & 5131 & $-5.59 \%$ & 1777754 & $42.83 \%$ & 39173096 & $52.07 \%$ \\
\hline 2008 & 6226 & $21.34 \%$ & 2099715 & $18.11 \%$ & 50865921 & $29.85 \%$ \\
\hline 2009 & 6865 & $10.26 \%$ & 2567928 & $22.30 \%$ & 68342322 & $34.36 \%$ \\
\hline
\end{tabular}




\begin{tabular}{|l|c|c|c|c|c|c|}
\hline 2010 & 8459 & $23.22 \%$ & 2410294 & $-6.14 \%$ & 84152357 & $23.13 \%$ \\
\hline 2011 & 8765 & $3.62 \%$ & 2431703 & $0.89 \%$ & 105368114 & $25.21 \%$ \\
\hline 2012 & 6294 & $-28.19 \%$ & 2281472 & $-6.18 \%$ & 107446306 & $1.97 \%$ \\
\hline 2013 & 5802 & $-7.82 \%$ & 2202267 & $-3.47 \%$ & 100079497 & $-6.86 \%$ \\
\hline 2014 & 5989 & $3.22 \%$ & 2031445 & $-7.76 \%$ & 106214196 & $6.13 \%$ \\
\hline 2015 & 5307 & $-11.39 \%$ & 2383355 & $17.32 \%$ & 120893897 & $13.82 \%$ \\
\hline
\end{tabular}

\subsubsection{The Unification of the Financial System}

In the absence of a unified financial system, ZTE cannot build a financial sharing center. ZTE's financial system is not fully unified: various areas produce various outcomes, and this affects the enterprise's overall efficiency. The group's reforms vis-à-vis financial system standardization underpin its drive to unify business processing. Under a standardized financial system, the financial department will divide its work, standardize the business process (and the tasks therein), carry out the timely rollout of transformational training for financial personnel, and reduce human costs. The presence of a standardized financial system provides institutional support for the construction of a financial shared service center.

\subsubsection{Upgrading to its Science and Technology Support Platform}

ZTE's science and technology support platform is the cornerstone of its financial shared service center: it builds a technical support system for information transmission and data storage between the group and its branches, and thus compensates for the ERP system that had been missing from the previous group. At the same time, financial sharing needs to pay more attention to security-especially security pertaining to information transmission among branches and groups. The maintenance of group data and information security is inseparable from the financial data-sharing and information security platform. A high-quality and efficient financial information platform can for an enterprise group reduce useless transmission processes and improve the flow of business operations and financial processing procedures.

\subsubsection{The Establishment of an Effective Employee Incentive Mechanism.}

To ensure human resources efficiency, it is necessary for ZTE to establish an effective employee incentive mechanism. In the past, with the decentralization of financial departments and given the different performance evaluation standards of various organizations, a broad range of assessments (some of which were unfair) were generated; this hampered employee enthusiasm and eventually led to the loss of human resources. ZTE needs to establish a unified and effective employee incentive system so that it can adopt a standardized financial system. The group should pay more attention to encouraging employee learning; additionally, individuals should be promoted so that they can adapt to the group's new financial system, and the group should resolve problems relating to redundancies or low efficiency levels as seen in the original financial organization. Finally, the old model pertaining to financial personnel needs to be transformed, whereupon a new mode of talent is shared and the group's human resources efficiency is ensured.

\section{Current Problems in the Financial Shared Service Centers of Chinese Enterprises}

\subsection{The Location of Financial Sharing Centers Increases Operating Costs}

The locations of financial shared service centers are constrained by economics, market, talent, and other factors. Most of China's centers are established in economically developed cities and regions such as Beijing, Shanghai, Guangzhou, and Shenzhen. Such locales are proximate to group enterprise headquarters, and this facilitates timely communication. Such siting does make it easier for financial 
shared service centers to recruit high-quality talent, but it runs counter to the original intention behind these centers (i.e., reduce costs overall). Indeed, the costs of establishing a financial shared service center will be higher in these highly developed cities than in smaller ones.

\subsection{Financial Work Cannot be Closely Linked to an Enterprise's Business}

At present, the financial shared service centers of Chinese enterprises have very much improved the efficiency with which they deal with simple business matters; they also facilitate the handling of a large amount of business, and make it easier to standardize financial accounting processes. However, in an enterprise group financial work is kept separate from business work, largely because their aims are so distant from one another: business management tends to be more of a formality, and financial work is undertaken by virtue of data analysis rather than real business situations. Moreover, on account of transmission delays, information obtained by the financial confidence system is often outdated, and it is difficult to connect the financial system of the financial shared service center to the business system.

\subsection{The Business Scope of Financial Shared Services is Narrow}

The core business of most enterprises' financial shared service centers is a single-module accounting business that cannot provide financial services for the whole of the enterprise group. Relatively speaking, the business scope of these centers is narrow and provides support only for certain branches or departments. To achieve the goal of financial information-sharing, large enterprises often need to establish multiple financial shared service centers. Furthermore, these centers cater mainly to the group's internal services; they do not provide outsourcing services to external enterprises.

\subsection{The Professional Competence of Traditional Financial accounting Personnel is Insufficient}

Traditional financial accountants cannot meet the needs that financial shared service centers fulfill. At present, most traditional accountants are competent only in financial accounting; only a few are management accountants. Such financial personnel have poor skill-set quality overall and are not sufficiently competent to fulfill their duties. With the establishment of a financial shared service center comes the redistribution of financial accounting work. The financial talent that enterprises need is held by those who can analyze financial and business data, implement cost budgets, manage performance, and provide to their enterprises support as they undertake strategic choices. As financial accounting personnel are freed from repetitive and single-minded traditional accounting tasks, enterprises must work to provide them with training on not only financial accounting but also management accounting.

\subsection{There is a Dearth of Effective Incentives among Financial Shared Service Personnel}

Financial work can be very repetitive, and the related business module is quite single-minded; furthermore, related standards are not always clear and unified, and it is difficult to evaluate the performance and quality of service in these centers. Concurrently, enterprises typically do not feature effective incentive mechanisms; this can frustrate employees, dampen their enthusiasm, and engender a sense of hopeless about on-the-job promotion. Needless to say, these suboptimal conditions can lead to the loss of human resources, obstruct the development of enterprise financial shared services, and hinder the creation of enterprise value. 


\section{Recommendations}

Having taken up the case of the ZTE group's financial shared service center,the researchers put forward the following suggestions as to how Chinese enterprises could establish or improve their own centers.

\subsection{Consideration the Location of Financial Shared Service Centers}

The location of financial sharing center is affected by many factors. When choosing a site within the territory of China, we should not only pay attention to economic development, talent market, distance from the headquarters and other factors, but, input cost factors must be considered as well. When choosing a site abroad, we should pay more attention to the laws and regulations of different regions and tax factors. When siting a financial shared service center in China, one should consider not only economic development, the talent market, and proximity to the enterprise headquarters, but also various cost factors. Second-tier cities with high levels of talent output and relatively low price levels, and which exhibit high levels of information technology development, are more suitable locations for financial shared service centers than first-tier cities such as Beijing, Shanghai, Guangzhou, and Shenzhen. When selecting the location for an overseas financial shared service center, it is important to consider the laws, regulations, and tax systems of various countries and regions. Only by following overseas regulations can one avoid obstructions that dovetail from legal issues. In terms of tax payments, countries do have different requirements, with enterprise tax conditions often diverging from the tax amounts enterprises actually pay. Additionally, labor costs differ from country to country. Naturally, siting in countries with high tax rates and high labor costs can increase enterprise costs, and so these are important considerations. Therefore, it is of great importance to be familiar with the regulations and taxes of the countries and regions covered by the service scope of the FINANCIAL sharing center. Therefore, the location of the financial sharing center should be selected from the countries or regions with policy support and certain tax incentives.

\subsection{Transform Financial Shared Service Centers into Profit Centers}

Financial sharing services can not only improve efficiency, it also reduces labor costs and save money. At present, most enterprises are faced with the problem of low efficiency. Through centralized training of accounting personnel, financial Shared service center can improve the professional quality of finance and reduce the management expense ratio, which is conducive to the positive impact of human capital on enterprise performance. A financial shared service center represents a kind of centralized organization mode, one that features the centralization of financial personnel and a separation from the business side; these features help mitigate fraud risk that can otherwise arise from the "blending" of financial and business personnel. The real-time and flexible control of funds can improve an enterprise's investment income while also generating additional income. A financial shared service center can not only save human costs, but also create enterprise value; it can be transformed into a profit center that can improve the rate of return on investment and, in capitalist enterprises, strengthen competitiveness.

\subsection{Improve Management Systems within Information Systems}

There is a risk of leakage in the processes within financial sharing service centers, and achieving an information system management system that is as perfect as possible is very important to sharing financial information. Establish a scientific system of authority, pay attention to the maintenance of information security. In terms of authority management, different levels of financial management 
authority are set according to different departments and divisions of labor. By giving individual financial personnel access to the enterprise's financial system, so that they can grasp the company's core data, and then achieve the goal of separation of responsibilities, to ensure the security of data. An enterprise can enhance its information system security index, hire security consultants, upgrade its information defense system, and prevent confidential information from being stolen. At the same time, the enterprise needs to automatically back up its data in its information system so as to preclude the loss of this tangible company asset.

\subsection{Promote talent training and the transformation of financial shared service centers.}

Under the old model, too many people were needed for a single, repetitive accounting job. With the establishment of a financial shared service center, financial personnel are freed from traditional (and sometimes menial) financial accounting tasks. To facilitate this transformation, it is very important that financial personnel receive training; additionally, a financial sharing scheme requires more management accounting talent, as opposed to financial accounting talent. During such training, financial personnel can learn which areas within their own skill sets require development. In the process, these individuals can help improve the concept of financial shared services; having achieved a deeper understanding of the importance of future economic decision-making for enterprise development, they can put forward constructive suggestions and, in the process, mitigate certain risks.

\subsection{Establish a science-based incentive mechanism for personnel.}

In financial work, there is often a lack of unified assessment standards, and the assessment of financial sharing center is difficult. Assessment standards are not uniform, easy to cause injustice, frustrate the enthusiasm of staff, lose talent. Among China's enterprises, the establishment of a unified assessment standard and a science-based incentive mechanism for personnel is conducive to strong development as they establish financial shared service centers. These facilities clarify job individual-level responsibilities, leverage a rotational method, are based on reasonable internal talent flows, carry out overall management tasks, and improve personnel work efficiencies. It is essential that enterprises define their promotion mechanism, especially in terms of education background or length of service; on-theground personnel can oversee the entire process, which will naturally improve transparency and give full play to the effectiveness of the enterprise's talent pool.

\section{Conclusions}

In today's increasingly severe economic situation, enterprises have to face to lower costs and more efficient operation mode improvement. Thus, the financial service sharing service center emerges and develops gradually. After more than 30 years of development and improvement, the establishment of the financial service sharing service center is originally to save cost and avoid. Risk considerations, to the enterprise to improve the core competitiveness of services. But we have to think, even if these financial service sharing service center has a perfect establishment plan, smooth operation success, the enterprise managers can rest easy?

Readers can learn from some high-efficiency processes and practices of ZTE Group to improve their own processes, and enterprises with problems can also think about why such problems occur and whether they can get some inspiration from the optimization scheme in this paper. Of course, the most meaningful part of this article is not to provide specific solutions, but to give many managers an idea. Financial sharing center optimization is also must continue to, and only by constantly looking for problems, from the view of found with continuous optimization to solve the problem, to make more 
efficient financial Shared services center, liberate more capital support enterprises to complete the construction of the core business, better service for the enterprise and group!

As for the inspiration to other enterprises in the establishment process of ZTE Group's FINANCIAL sharing center, the specific implementation can directly learn from the case of ZTE Group's financial sharing center. As for how to promote the implementation of these optimizations, there are the following parts:

1) The optimization of the FINANCIAL sharing center discussed in this paper is based on the successful construction of the financial sharing service center established by ZTE Group, and Suggestions and optimization for the financial sharing center of Chinese enterprises are put forward. The purpose of any form of optimization is to better serve the enterprise group. Therefore, it cannot be separated from the target and vision of the group, nor can it be separated from the group itself to adopt inappropriate methods and means. Any appropriate advanced process needs to be combined with the actual situation of their own units, in order to achieve the best results.

2) The optimization of the financial sharing center is a persistent work that even needs the cooperation of multiple departments. Therefore, we must first get the approval and support of management. Only with their help can the optimization work of the financial sharing center proceed smoothly. Therefore, how to find the problem in time and solve the problem efficiently is the homework that every management personnel needs to do.

3) The optimization of the financial sharing center can be helped by "external forces". When problems occur in the financial sharing center of an enterprise, although the best solution is not to maintain the status quo, how to carry out reasonable optimization to help the whole process the most, can make the financial sharing center the most efficient need a lot of smart measures. Thus, on the one hand, enterprise group can share directly from other financial centers of some successful cases, on the other hand can be hired experienced expert professional guidance in the presence of this unit, also can through the system vendor to discuss with advanced methods such as learned many advanced management and operation, save the cost of trial and error for financial sharing center optimization, also can save time and manpower, to optimize the financial center of Shared state quickly.

4) When conditions allow, a special functional department shall be established in the financial sharing center, which shall be responsible for implementing the concept of risk management and putting it into action. It shall supervise and inspect the process and other problems of the financial sharing center from time to time, so as to timely discover, control and optimize risks as much as possible.

ZTE as a group, with relatively mature experience in financial sharing center, does not have many problems in process and other aspects. Therefore, this paper is limited on the problem which mainly comes from literature rather than cases.

\section{Acknowledgments}

This work was supported by the Gachon University research fund of 2020. (GCU-202002800001)

\section{References}

[1] A. Kris, B. Quinn, R. Cooke, Shared Services: Mining for Corporate Gold, Financial Times Prentice Hall, (2000), pp.256.

[2] P. Moller, Implementing Shared Services in Europe, Treasury Management International, (1997), Vol.6, No.1, pp.121123.

[3] B. Bergeron, Essentials of Shared Services, Translated by Yanqing, China Renmin University Press, (2004) 
[4] A. Kris, M. Fahy, Service Sharing - New Competition series, China Renmin University Press, (2004)

[5] L. K. Chen, Financial Sharing Service Application Analysis based on flat Management Theory, Finance \& Accounting Communications, (2014), No.14, pp.51-53, 10.16144/j.cnki.issn1002-8072.2014.11.034

[6] Y. Q. Zhang, Reform of accounting Industry: An Analysis of Shared intensive Operation and Future Path - Based on the views of enterprise Groups, Friends of Accounting, (2014), No.1, pp.27-30, 10.3969/j.issn.1004-5937.2014.30.007

[7] W. Y. Li, D. J. Liu, Innovation of Financial Management Mode and Case Study in civil Engineering Industry - Practice of Financial Sharing Center Service of China Communications Second Aviation Bureau, Monthly Journal of Accounting, (2015), No.14, pp.16-25, 10.19641/j.cnki.42-1290/f.2015.04.004

[8] X. H. Jian, Using Financial Sharing to Improve Corporate Performance Management, China Accounting Journal, (2014), Vol.9, No.1, pp.1-2.

[9] H. Z. Zhou, A Brief Discussion on the Construction of Financial Sharing Service Center of Group Enterprises, Finance \& Economics, (2015), No.11, pp.289, 10.16266/j.cnki.cn11-4098/f.2015.07.250

[10] G. L. Li, Q. L. Zhang, Future Development Trend of Financial Sharing Services, Chinese Certified Public Accountants, (2012), No.12, pp.26-28.

[11] Y. He, F. Zhou, J. Li, An Empirical Study on the Effectiveness of Financial Sharing Services in Chinese Enterprise Groups — Empirical Data from 2004 to 2008, Economics and Management Research, (2013), No.8, pp.57-65, $10.3969 /$ j.issn.1000-7636.2013.08.006

[12] C. H. Jin, X. Q. Ge, Y. Liu, Research on the Connotation, Mechanism and Construction of Resource Sharing in Soft Science Research, Science of Science and Management of Science and Technology, (2007), No.4, pp.16-19, 10.3969/j.issn.1002-0241.2007.04.003

[13] Q. L. Zhang, C. X. Zhang, Research on Informatization Construction of Financial Shared Service Center, Chinese Certified Public Accountants, (2012), No.6, pp.48-52, 10.3969/j.issn.1009-6345.2012.06.017

[14] Q. L. Zhang, H. Dong, Discussion and Selection of Financial Sharing Service Model, Chinese CPA, (2012), No.2, pp.66-69. 